\title{
Sequence variation in the $\alpha$-toxin encoding plc gene of Clostridium perfringens strains isolated from diseased and healthy chickens
}

\author{
Lone Abildgaard ${ }^{\text {a,d }}$, Ricarda M. Engberg ${ }^{\text {a }}$, Karl Pedersen ${ }^{\mathrm{b}, \mathrm{c}}$, Andreas Schramm ${ }^{\mathrm{d}}$, Ole Hojberg a,* \\ ${ }^{a}$ Institute of Animal Health, Welfare and Nutrition, Faculty of Agricultural Sciences, University of Aarhus, P.O. Box 50, DK-8830 Tjele, Denmark \\ ${ }^{\mathrm{b}}$ Department of Poultry, Fish and Fur Animals, Danish Veterinary Institute, Technical University of Denmark, Hangøvej 2, DK-8200 Aarhus N, Denmark \\ ${ }^{\mathrm{c}}$ Faculty of Life Sciences, University of Copenhagen, DK-1870 Frederiksberg C, Denmark \\ ${ }^{\mathrm{d}}$ Department of Biological Sciences, Microbiology. University of Aarhus, Ny Munkegade, Building 1540, DK-8000 Aarhus C, Denmark
}

\section{A R T I C L E I N F O}

\section{Article history:}

Received 13 September 2008

Received in revised form 31 October 2008

Accepted 3 November 2008

\section{Keywords:}

$\alpha$-Toxin

plc gene

C. perfringens

\begin{abstract}
A B S T R A C T
The aim of the present study was to analyse the genetic diversity of the $\alpha$-toxin encoding plc gene and the variation in $\alpha$-toxin production of Clostridium perfringens type A strains isolated from presumably healthy chickens and chickens suffering from either necrotic enteritis (NE) or cholangio-hepatitis. The $\alpha$-toxin encoding plc genes from 60 different pulsed-field gel electrophoresis (PFGE) types (strains) of $C$. perfringens were sequenced and translated in silico to amino acid sequences and the $\alpha$-toxin production was investigated in batch cultures of 45 of the strains using an enzyme-linked immunosorbent assay (ELISA) approach. Overall, the truncated amino acid sequences showed close similarity ( $>98 \%$ at the amino acid level) to previously reported sequences from chicken-derived $C$. perfringens isolates. Variations were however observed in 23 out of 379 aa positions leading to the definition of 26 different $\alpha$-toxin sequence types among the 60 strains. Moreover, a type II intron of 834 non-coding nucleotides was identified in the plc gene of three of the investigated strains. The in vitro $\alpha$-toxin production investigated in 45 of the strains, including the three harbouring the intron, revealed no correlation between PFGE type, $\alpha$ toxin sequence type, health status of the host chickens and level of $\alpha$-toxin production. It is therefore concluded that neither plc gene type nor $\alpha$-toxin production level seems to correlate to origin (healthy or diseased chicken) of the $C$. perfringens strains.
\end{abstract}

(c) 2008 Elsevier B.V. All rights reserved.

\section{Introduction}

Necrotic enteritis (NE) is a common disease of broiler chickens, mediated by Clostridium perfringens type A and characterised by decreased growth rate, intestinal damage and eventually death (Kaldhusdal and Hofshagen, 1992; Wages and Opengart, 2003). In healthy chickens, the enteric population of $C$. perfringens is typically genetically heterogeneous (judged by PFGE patterns), whereas in chickens suffering from NE, one or two virulent strains tend to dominate (Engström et al., 2003; Nauerby et al.,

\footnotetext{
* Corresponding author. Tel.: +45 8999 1183; fax: +45 89991120. E-mail address: ole.hojberg@djf.au.dk (O. Hojberg).
}

2003; Barbara et al., 2008). The $\alpha$-toxin produced by $C$. perfringens has traditionally been considered a prerequisite virulence factor for development of NE (Al-Sheikhly and Truscott, 1977; Fukata et al., 1988; Williamson and Titball, 1993; Awad et al., 1995; Thompson et al., 2006; Kulkarni et al., 2007, 2008; Cooper et al., 2009), though the recent identification of necrotic enteritis toxin B (NetB) and proteolytic enzymes in relation to NE has questioned this conception (Keyburn et al., 2006, 2008; Olkowski et al., 2008).

The $\alpha$-toxin is nevertheless a hazardous enzyme possessing phospholipase $\mathrm{C}$ as well as sphingomyelinase activity (Saint-Joanis et al., 1989; Titball and Basak, 2004). It contains an $\alpha$-helical $\mathrm{N}$-terminal domain (residues 1-246) encompassing the active site (Titball, 1993) and a 
$\beta$-sandwich C-terminal domain (residues 247-255) considered essential for toxicity (Titball et al., 1991, 1993; Nagahama et al., 1998; Naylor et al., 1998). The $\alpha$-toxin is encoded by the plc gene reported to be highly conserved in $C$. perfringens strains isolated from diseased chickens, with variations in only nine out of 397 deduced amino acid positions (Sheedy et al., 2004). Further knowledge about variations in the plc gene is important to obtain, however, since it may reveal changes in the above-outlined $\alpha$-toxin structure and hence bacterial virulence. Moreover, it is crucial for designing real-time PCR protocols targeting the plc gene. The present study evaluated and modified probes and primers designed by Skånseng et al. (2006) for investigating variation of the plc gene as well as evaluating its relation to $\alpha$-toxin production and origin of the host strains.

\section{Materials and methods}

\subsection{Bacterial strains}

To investigate genetic diversity among $C$. perfringens in Danish broiler chickens, Nauerby et al. (2003) collected 279 isolates between 1997 and 2002 from healthy chickens as well as chickens suffering from necrotic enteritis or cholangio-hepatitis. All isolates were shown to belong to toxin type A and grouped according to pulsedfield gel electrophoresis (PFGE) profiles into 48 types (strains). The present study included isolates representing 42 of the 48 PFGE types (culturable representatives for the remaining 6 PFGE types were no longer available) as well as 18 PFGE types isolated in the same study, but not previously reported. Strains named $\mathrm{Sx}$ ( $\mathrm{x}=$ PFGE type) refer to the 48 PFGE types reported by Nauerby et al. (2003). Strains named Tx represent the 18 remaining PFGE types. The $\alpha$-toxin sequences were compared to that of $C$. perfringens strain 13 (GenBank accession number NC_003366, Shimizu et al., 2002); a commonly used human-derived reference strain originally described by Mahony and Moore (1976).

The strains were cultured on blood agar (Oxoid, Basingstoke, England). Colonies with haemolytic activity were transferred to anoxic reinforced clostridial medium (RCM) (Merck, Darmstadt, Germany) and incubated at $37{ }^{\circ} \mathrm{C}$ for $24 \mathrm{~h}$ or until turbidity was clearly seen. The purity and the $C$. perfringens identity of the cultures were checked by phase-contrast microscopy and growth on Tryptose Sulfite Cycloserine (TSC) agar plates (Merck) supplemented with 4-methylbelliferyl phosphate (MUP) (Merck).
Lecithinase activity of selected strains was tested on MUP supplemented TSC plates supplemented further with egg yolk emulsion (Oxoid) and haemolytic activity was tested on $5 \%$ calf blood agar.

\subsection{DNA extraction, PCR and sequence analysis}

DNA was extracted from $1 \mathrm{~mL}$ culture using a FastDNA SPIN kit (Qbiogene, Carlsbad, CA) according to the manufacturer's instructions. The plc gene was PCR amplified from extracted DNA or cDNA using the primer pair designed by Sheedy et al. (2004) (Table 1). The plc gene was amplified in $50 \mu \mathrm{L}$ volumes containing $1 \times$ PCR (polymerase chain reaction) buffer, BSA $(0.4 \mu \mathrm{g} / \mu \mathrm{L}$ final concentration), 1 pmol each primer, $200 \mu \mathrm{M}$ each dNTP, 4 U DyNAzyme II DNA polymerase (Finnzymes Oy, Espoo, Finland), and $3 \mu \mathrm{L}$ of DNA extract. Thermal cycling conditions were: $1 \mathrm{~min}$ at $94^{\circ} \mathrm{C}$, followed by 30 cycles of $94{ }^{\circ} \mathrm{C}$ for $1 \mathrm{~min}, 47^{\circ} \mathrm{C}$ for $1 \mathrm{~min}, 72{ }^{\circ} \mathrm{C}$ for $1 \mathrm{~min}$, and a final extension at $72{ }^{\circ} \mathrm{C}$ for $10 \mathrm{~min}$. The obtained PCR products were purified using the QIAquick kit (QIAGEN, Hilden, Germany) according to the manufacturer's instructions. Purified PCR products were sequenced using the six primers listed in Table 1, the ABI Prism Big Dye kit, and the following PCR conditions: 99 cycles of $95{ }^{\circ} \mathrm{C}$ for $10 \mathrm{~s}$, $50{ }^{\circ} \mathrm{C}$ for $5 \mathrm{~s}$, and $62{ }^{\circ} \mathrm{C}$ for $4 \mathrm{~min}$. Sequenced PCR products were purified using a sodium acetate/ethanol precipitation step and read using an ABI 3730xl DNA analyzer (Applied Biosystems, Nærum, Denmark). The plc gene sequences were manually aligned according to their deduced amino acid sequences using BioEdit version 7.0.2 (Hall, 1999) and all alignments were refined by manual inspection. Phylogenetic analysis was performed with CLC Free Workbench version 3.0 (CLC Bio A/S, Aarhus, Denmark) using the neighbour-joining approach. Bootstrap analysis was performed with 100 resamplings.

\subsection{Nucleotide sequence accession numbers}

The plc gene sequences have been deposited in the GenBank database under accession numbers EU839779 to EU839838.

\subsection{RNA analysis}

Samples of RNA from strains S3, S4, S5, T2, and T9 were preserved by transferring aliquots of $0.5 \mathrm{~mL}$ culture to $2 \mathrm{~mL}$ microcentrifuge tubes containing $1 \mathrm{~mL}$ RNA protect (QIAGEN). Total RNA was isolated using the RNAprotect

Table 1

PCR primers used to amplify and sequence the plc gene.

\begin{tabular}{lll}
\hline Name & Sequence $\left(5^{\prime}-3^{\prime}\right)$ & Target position $^{\mathrm{a}}$ \\
\hline ss2 ${ }^{\mathrm{b}}$ & CTT GAA AAA AAT T*AA CGG & 48561 \\
Ss3 & TGT AAA TAC CAC CAA AAC C & 49809 \\
$289 \mathrm{~F}$ & TTC TGG GAT CCT GAT ACA GAT AA & 48878 \\
$381 \mathrm{R}$ & AGG GGA ATC ACA AAA TAA GA & 49402 \\
$477 \mathrm{~F}$ & AGA TAC TCC ATA TCA TCC T & 49066 \\
$551 \mathrm{R}$ & TTT GA(A/G) ACT TTT GCA GA & 49124 \\
\hline
\end{tabular}

a Target position is relative to $C$. perfiingens strain 13 complete genome (accession number NC_003366).

b The ss2 primer designed by Sheedy et al. (2004) has a nucleotide insert (marked by ${ }^{*}$ ) compared to the sequence of $C$. perjriyigens strain 13 . 
protocol (QIAGEN) which includes enzymatic lysis, proteinase $\mathrm{K}$ digestion, and mechanical disruption, and purified using the RNeasy mini kit (QIAGEN) according to the manufacturer's recommendations. The RNA was eluted twice in $20 \mu \mathrm{L}$ RNase free water. The QIAGEN RNase-Free DNase Set was applied during RNA extraction to remove DNA. The concentration and purity of the RNA was determined as absorbance at $260 \mathrm{~nm}$ and $280 \mathrm{~nm}$ in a NanoDrop ND-1000 Spectrophotometer (Thermo Fisher Scientific, Wilmington, DE, USA). The RNA was stored at $-80{ }^{\circ} \mathrm{C}$ for a maximum of one week before cDNA synthesis. Reverse transcription (RT) was performed using the firststrand cDNA protocol and SuperScript ${ }^{\mathrm{TM}}$ III reverse transcriptase (Invitrogen, Carlsbad, CA, USA) according to the manufacturer's recommended protocol with 100 ng RNA and $100 \mathrm{ng}$ random hexamer primers (Invitrogen) per reaction. The thermal profile was as follows: $25^{\circ} \mathrm{C}$ for $5 \mathrm{~min}, 50^{\circ} \mathrm{C}$ for $60 \mathrm{~min}, 70^{\circ} \mathrm{C}$ for $15 \mathrm{~min}$. The cDNA products were PCR amplified using the primers ss2 and $551 \mathrm{R}$ and PCR products were evaluated on agarose gels.

\subsection{Quantification of $\alpha$-toxin}

In a separate study (Abildgaard, 2008), analyzing in more detail the $\alpha$-toxin production of some of the investigated $C$. perfringens isolates, production of $\alpha$-toxin was observed to peak in late log phase, as previously reported for other C. perfringens toxins (Sayeed et al., 2005; Fisher et al., 2006), and no sign of $\alpha$-toxin degradation was observed within a $24 \mathrm{~h}$ period, as also reported by Gholamiandekhordi et al. (2006). Batch cultures of the $C$. perfringens isolates were therefore propagated anaerobically in RCM broth at $37^{\circ} \mathrm{C}$ for $24 \mathrm{~h}$, where after the production of $\alpha$-toxin was quantified by enzyme-linked immunosorbent assay (ELISA), similar to the approach used by Gholamiandekhordi et al. (2006). Samples ( $1 \mathrm{~mL}$ ) were centrifuged at $16,000 \times g$ for $15 \mathrm{~min}$ and the supernatant was filtrated through a $0.2 \mu \mathrm{m}$ cellulose acetate sterile filter (Schleicher \& Schuell, Dassel, Germany). Filtrate $(100 \mu \mathrm{L})$ was transferred to microtiter plates coated with $\alpha$-toxin antibody or non-specific antibodies (blank) and the concentration of $\alpha$-toxin in each sample was determined using a Bio-X Alpha toxin ELISA kit according to the instructions of the manufacturer (Bio-X Diagnostics, Jemelle, Belgium). The incubation of the microplate was prolonged to $15 \mathrm{~min}$. $\mathrm{OD}_{450}$ was determined in a plate reader (PowerWave X, Bio-Tek Instruments Inc., Winooski, VT, USA) and converted to $\alpha$-toxin units by the use of a dilution series of phospholipase $C$ (P7633, Sigma-Aldrich) containing 0.005-0.062 units $/ \mathrm{mL}$. If the sample concentrations were higher than the linear range of the standard concentrations, the samples were diluted $2 \times$ or $10 \times$. Samples from three independent growth experiments were analysed, and average values and standard deviations calculated.

\section{Results}

Overall the $\alpha$-toxin sequences were highly similar ( $>89 \%$ at the nucleic acid level and $>98 \%$ when translated to amino acid level) to the previously reported sequences isolated from chickens (Sheedy et al., 2004). Variations were however observed in 23 out of the 397 deduced amino acid positions leading to a tentative definition of 26 different $\alpha$-toxin sequence types among the 60 PFGE types (Table 2). The sequence variations could not be related to health status of the flocks from which the $C$. perfringens strains were isolated; all of the $\alpha$-toxin sequence types identified in more than one PFGE type were found in healthy as well as diseased chickens. Sequence type I had only one amino acid different to $C$. perfringens strain 13 and was the most common $\alpha$-toxin sequence type, found in 19 of the 60 strains. A dendrogram containing 48 of the 60 PFGE types (Nauerby et al., 2003) was compared to a neighbour-joining tree of the respective plc sequences and no correlation between PFGE type and $\alpha$-toxin sequence type was found (data not shown).

The gene sequence of three of the strains, S3, S4, and S5 had an insertion of 834 non-coding nucleotides at the $5^{\prime}$ end, right next to amino acid position 113, corresponding to the N-terminal domain encompassing the catalytic site. As indicated by the names, the three isolates had different pulsed-field gel electrophoresis profiles and were obtained from different healthy birds (Nauerby et al., 2003). Ignoring the insert, the truncated $\alpha$-toxin amino acid sequences of the three isolates were all identified as type $\mathrm{Vb}$ (Table 2). The presence of insertion is shown in Fig. 1 where the DNA of strain S3, S4, and S5 is 834 bp longer than the DNA of the two reference strains. The mRNA of strain S3, S4, and S5 is however the same length as the reference strains as shown on the right panel of Fig. 1 where the mRNA encoding the plc gene has been reverse transcribed to cDNA for comparison. A weak band of the same length as the unspliced DNA is visible in the cDNA lane for strain S5. This could be due to incomplete removal of the intron during mRNA processing but is more likely due to incomplete removal of DNA during RNA purification. Grown in batch cultures, strain S3 as well as strain S4 was observed to produce $\alpha$-toxin at levels comparable to stains without the insert, whereas strain S5 showed low $\alpha-$ toxin production in the media tested (Fig. 2). The $\alpha$-toxinmediated haemolytic and lecithinase activity for strain $\mathrm{S} 3$, S4, and S5 were determined by growing the strains on blood agar and egg yolk agar, respectively, and compared with two reference strains (T2 and T16) without inserts. All three strains as well as the reference strains showed both types of enzyme activity, however with varying degree. Thus, the low $\alpha$-toxin producing strain S5 (Fig. 2) showed altered colony morphology on blood agar and only very weak haemolytic activity. In general, however, the haemolytic and lecithinase activity measures obtained on agar plates could not be directly correlated to the $\alpha$ toxin levels determined in the batch cultures (Fig. 2) and are considered more qualitative measures.

The $\alpha$-toxin production varied considerably between the tested strains however, the production levels observed for the individual strains were highly reproducible, as indicated by the standard deviations (Fig. 2). The variation in $\alpha$-toxin production of the investigated strains ranged from below detection limit to 0.12 units $/ \mathrm{mL}$ (Fig. 2). Production of more than 0.1 units $/ \mathrm{mL}$ was observed for PFGE types S11, S13, T7, and T9, all belonging to different 
Table 2

Variable amino acid positions of the defined $\alpha$-toxin sequence types.

\begin{tabular}{|c|c|c|c|c|c|c|c|c|c|c|c|c|c|c|c|c|c|c|c|c|c|c|c|c|}
\hline \multirow{2}{*}{$\begin{array}{l}\alpha \text {-Toxin } \\
\text { sequence type }{ }^{a}\end{array}$} & \multicolumn{22}{|c|}{ Amino acid position $^{\mathrm{b}}$} & \multirow[t]{2}{*}{ PFGE types ${ }^{c}$} & \multirow[t]{2}{*}{$\mathrm{NE}^{\mathrm{d}}$} \\
\hline & 7 & 9 & 13 & 15 & 20 & 22 & 47 & 54 & 71 & 74 & 103 & 149 & 175 & 185 & 190 & 195 & 202 & 205 & 227 & 276 & 363 & 373 & & \\
\hline Strain 13 & K & $\mathrm{L}$ & $\mathrm{T}$ & A & A & A & V & $\mathrm{L}$ & $\mathrm{E}$ & $\mathrm{H}$ & D & $\mathrm{L}$ & G & $\mathrm{E}$ & $\mathrm{Y}$ & A & D & A & $\mathrm{T}$ & D & $\mathrm{P}$ & I & 1 & \\
\hline Type I & & & A & & & & & & & & & & & & & & & & & & & & 19 & 13 \\
\hline Type II & & & A & & & & & & & & & & & & & & & & & & & V & 4 & 1 \\
\hline Type IIb & & & A & & & & & & & & & & $\mathrm{R}$ & & & & & & & & & V & 1 & \\
\hline Type IIc & & & A & & & & & & & & & & $\mathrm{R}$ & K & & & & & & & & & 1 & \\
\hline Type IId & & & A & & & & & & & & & & & & & & & & I & & & V & 2 & 1 \\
\hline Type IIe & $\mathrm{N}$ & & A & & & & & & & & & & & & & & & & I & & & V & 1 & 1 \\
\hline Type IIf & & & A & & & & & & & & & & & & $\mathrm{F}$ & & & & & & & & 2 & 1 \\
\hline Type IIg & & & A & & & & & & & & & & & & & & & & & & & $\mathrm{L}$ & 1 & \\
\hline Type III & & & & V & & V & & $\mathrm{M}$ & D & & & I & & & & & & & & & & V & 0 & \\
\hline Type IIIb & & & & V & D & V & & $\mathrm{M}$ & $\mathrm{D}$ & & & & & & & & & & & & & & 1 & \\
\hline Type IV & & & A & & & & & $\mathrm{M}$ & & & & & & & & & & & & & & V & 0 & \\
\hline Type IVa & & & A & & & & & $\mathrm{M}$ & & & & & $\mathrm{R}$ & & & & & & & & & V & 1 & \\
\hline Type V & & & A & & & & & & & & & & & & & & A & $\mathrm{T}$ & & & & & 0 & \\
\hline Type Vb & & & A & & & & & & & & & & & & & & A & $\mathrm{T}$ & & & & & 5 & 1 \\
\hline Type Vc & & $\mathrm{F}$ & A & & & & & & & $\mathrm{N}$ & & & & & & V & A & $\mathrm{T}$ & & & & V & 1 & \\
\hline Type VI & & & A & & & & & & & & & & & & & V & $\mathrm{N}$ & & & & & V & 6 & 4 \\
\hline Type VIb & & & A & & & & & & & & & & $\mathrm{R}$ & & & V & $\mathrm{N}$ & & & & & V & 1 & \\
\hline Type VIc & & & A & & & & & & & & $\mathrm{Y}$ & & & & & V & $\mathrm{N}$ & & & & & V & 1 & \\
\hline Type VId & & & A & & & & & & & & & & & & $\mathrm{F}$ & V & $\mathrm{N}$ & & & $\mathrm{N}$ & & V & 1 & \\
\hline Type VIe & & & A & & & & & & & & & & & & & V & & & & & & V & 2 & 1 \\
\hline Type VII & & & A & & & $\mathrm{S}$ & I & & & & & & & & & V & & & & & & V & 1 & \\
\hline Type XIII & & & & & & & & & & & & & & & & & & & & & & V & 1 & \\
\hline Type XIIIa & & & & & & & & & & & & & & & & V & & & & & & V & 1 & 1 \\
\hline Type XIIIb & & & & & & & & & & & & & & & & V & & & & & $\mathrm{S}$ & V & 1 & \\
\hline Type IX & & & & & & & I & & & & & & & & & & A & & & & & V & 1 & \\
\hline Type IXa & & & & & & & I & & $Q$ & & & & & & & & A & & & & & V & 2 & \\
\hline Type IXb & & & & & & & I & & $\mathrm{R}$ & & & & & G & & & A & & & & & V & 1 & \\
\hline \multirow[t]{2}{*}{ Type X } & & & & & & & I & & & & & & & & & & & & & & & $\mathrm{L}$ & 1 & \\
\hline & & & & & & & & & & & & & & & & & & & & & & & 60 & 24 \\
\hline
\end{tabular}

${ }^{\text {a }}$ The $\alpha$-toxin sequence types I-V were previously defined by Sheedy et al. (2004). Types VI-XI and subtypes of all 11 types were defined in the present study.

b The amino acid sequence positions of the non-conserved amino acids are shown above the alignment and refer to the full-length $\alpha$-toxin protein (397 amino acids).

c Number of strains (PFGE types) represented by the individual $\alpha$-toxin sequence types.

d Number of PFGE types isolated from chickens suffering from necrotic enteritis.

$\alpha$-toxin sequence types. PFGE type T7 and T9 were only isolated from chickens suffering from NE, PFGE type S13 was obtained from healthy chickens only, whereas PFGE type S11 was isolated from healthy as well as diseased chickens. Likewise, low $\alpha$-toxin producers were represented by strains of different $\alpha$-toxin sequence types and originated from healthy as well as diseased chickens. In

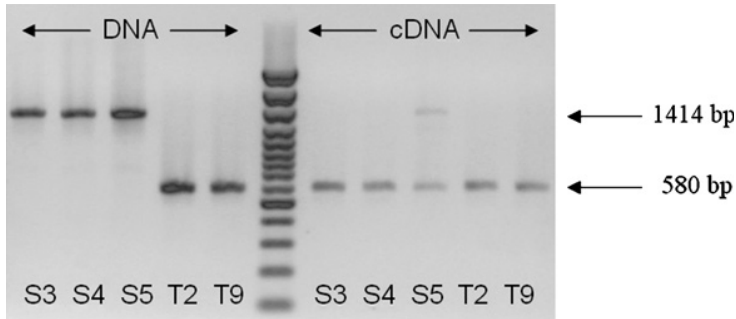

Fig. 1. PCR amplification of the plc gene using the primers ss 2 and 551R. Lanes 1-5 DNA, Lanes 7-11 cDNA. Strain designations for the lanes are as follows lane 1 and 7, S3; lane 2 and 8, S4; lane 3 and 9, S5; lane 4 and 10, T2; lane 5 and 11, T9; lane 6, molecular size marker (from the bottom 100, $200,300,400,500,600,700,800,900,1000,1200,1500,2000,3000)$. Size of amplicon without insertion: $580 \mathrm{bp}$, with insertion: $1414 \mathrm{bp}$. The weak band in lane 9 is probably due to incomplete removal of DNA from the RNA. general therefore, no correlation between $\alpha$-toxin sequence type, $\alpha$-toxin production, PFGE type or chicken health status could be observed (Table 2 and Fig. 2).

\section{Discussion}

In a previous study, the plc gene sequence of 25 different $C$. perfringens strains was analyzed and the strains were divided into five $\alpha$-toxin sequence types (I-V) according to their deduced amino acid sequence (Sheedy et al., 2004). We analyzed a total of 60 strains (PFGE types) and found 19 strains belonging to sequence type I, four strains belonging to sequence type II, but none belonging to sequence types III, IV and V (Table 2 ). In addition to the five $\alpha$-toxin sequence types defined by Sheedy et al. (2004), we defined further 23 $\alpha$-toxin sequence types each represented by 1-6 of the investigated PFGE types (Table 2). Though the definition of the $\alpha$-toxin sequence types is somewhat tentative, our data nevertheless illustrates that the variation in the chickenderived C. perfringens $\alpha$-toxin sequence is somewhat higher than reported by Sheedy et al. (2004). Sequence type I was however the most prevalent in both studies.

Zinc ions are essential for the catalytic activity of the $\alpha$ toxin (Titball, 1993) and the amino acids (Trp1, His11, 


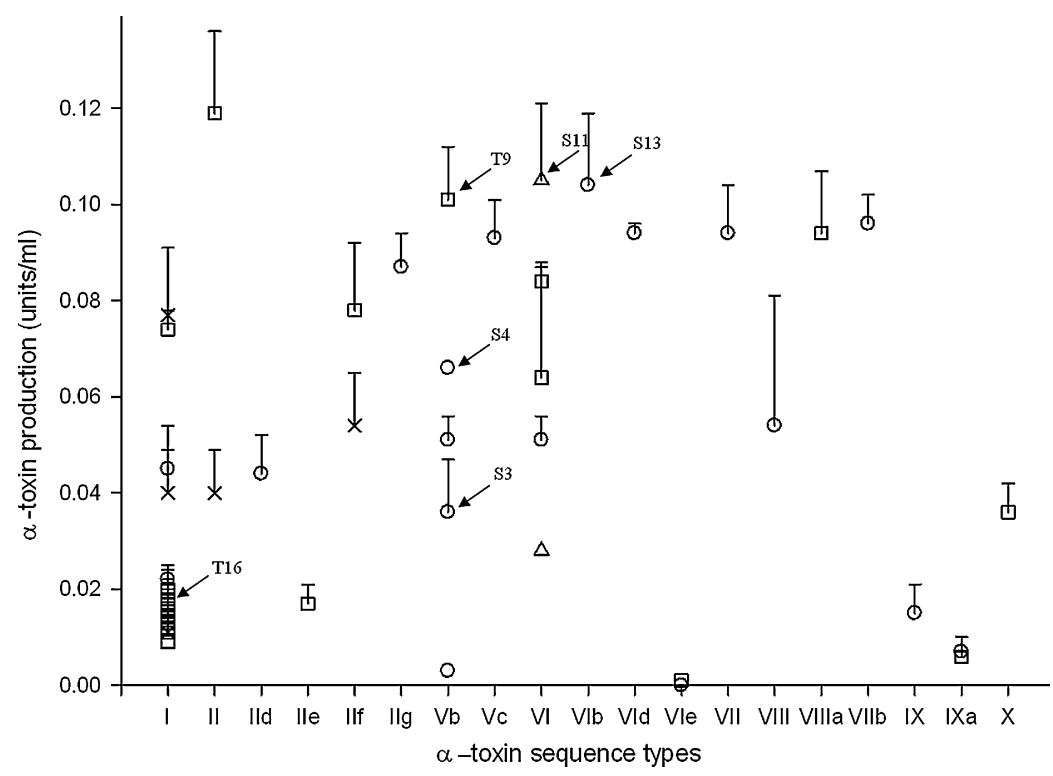

Fig. 2. Production of $\alpha$-toxin by $C$. perfringens strains (PFGE types) belonging to different $\alpha$-toxin sequence types. The strains were grown 24 h at $37{ }^{\circ} \mathrm{C}$ in RCM batch cultures. Health status of the chicken from which representatives of the PFGE types were isolated are indicated as: ( $\bigcirc$ ) healthy; ( $\square$ ) diseased; $(\triangle)$ both healthy and diseased; $(\times)$ health status unknown. Data are presented as average values of duplicates or triplicates and error bars indicate standard deviations.

Asp56, His68, Asp130, His136, His148, and Glu152) that are coordinated by the zinc ions (Hough et al., 1989; Naylor et al., 1998; Justin et al., 2002; Clark et al., 2003; Titball and Basak, 2004). Another ion essential for the activity of $\alpha$ toxin is calcium (Moreau et al., 1988) and the calcium protein ligands are Glu32, Asp269, Gly271, Thr272, Asp273, Asp293, Asn294, Gly296, Asn297, Asp298, Asp336, and Ala337. (Titball and Basak, 2004). Tyr275, Tyr307, and Tyr331 are also important for full toxicity of the toxin (Alape-Gíron et al., 2000). Tyr57 and Tyr65 play a role in the binding to membranes, but not in the catalytic activity (Nagahama et al., 2006). We did not observe any amino acid substitutions in these vital positions indicating that the sequence variations revealed by our results are unlikely to influence the activity of the toxin.

The novel plc sequence information presented in this study illustrates however that previously published probes and primers may need revision; the reverse primer of the primer-probe set published for real-time PCR quantification of $C$. perfringens (Skånseng et al., 2006) has mismatches at three different positions, one of them in up to 57 of the 60 sequences and the probe has a mismatch to 8 of the 60 sequences (data not shown). Likewise, mismatches were found to other commonly used primers and probes (Meer and Songer, 1997; Al-Khaldi et al., 2004). Mismatches like this may lead to an underestimation of the target sequence in the real-time PCR process.

Three of the investigated strains (S3, S4, and S5) had an insertion in the plc gene of 834 non-coding nucleotides that were observed to be excised (spliced) from the mRNA during transcription. The sequence of the insertion matched the group II intron reported by Ma et al. (2007) and may therefore be a common feature in the plc gene of $C$. perfringens isolated from chickens. The $\alpha$-toxin production level, the $\alpha$-toxin-mediated lecithinase activity, and the hemolytic activity for strain S3 and S4 were within the normal range of the other $C$. perfringens strains tested. This further supported that the insertion was removed during RNA processing and therefore did not affect the $\alpha$-toxinmediated activities of the three strains.

The in vitro $\alpha$-toxin production of the 60 isolates, representing separate PFGE types and grouped into $28 \alpha-$ toxin sequence types, varied within a range of approximately one decade and showed no correlation between $\alpha$-toxin sequence type and $\alpha$-toxin production levels (Fig. 2). In an investigation of 63 C. perfringens isolates allocated to 35 PFGE types, Gholamiandekhordi et al. (2006) reported a similar range of variation in $\alpha$-toxin production; however isolates belonging to the same strain were observed to produce equal amounts of $\alpha$ toxin. The VirR/VirS two-component regulatory system regulates the transcription of the plc gene (Ba-Thein et al., 1996; Banu et al., 2000) and variations at the regulatory level may be of much higher importance for variation in $\alpha$-toxin production of the individual strains than variations in the structural gene per se.

The lack of correlation between in vitro $\alpha$-toxin production level of the strains and health status of the chickens of origin as observed in the present study is in accordance with observations from recent studies (Gholamiandekhordi et al., 2006; Timbermont et al., 2008). However, these observations do not themselves question the role of the $\alpha$-toxin in NE development, since an in vitro capacity measure like this neither reflects actual in situ production rates directly nor does it take other predisposing factors like coccidia-mediated tissue lesions into account. Further, in vitro $\alpha$-toxin production by $C$. perfringens type A may vary considerably depending on the culture media used (Fernandez-Miyakawa et al., 2007). But without doubt, the new and important reports on other 
C. perfringens virulence factors, like NetB (Keyburn et al., 2008) and proteolytic enzyme (collagenase) activity (Olkowski et al., 2008), in relation to clinical and subclinical NE call for a thorough evaluation of the potential virulence factors and our understanding of the disease.

\section{Conclusion}

The variation in plc sequence is generally low; however 23 new $\alpha$-toxin sequence types were nevertheless defined in addition to the five previously defined sequence types. A type II intron of 834 non-coding nucleotides, removed during RNA processing, was found in three of the investigated strains and appears to be a rather common feature in the DNA encoding the N-terminal domain of the C. perfringens $\alpha$-toxin. The $\alpha$-toxin production was highly variable among strains, and the production level could neither be predicted from $\alpha$-toxin gene type, PFGE type (strain), nor health status of the chicken flocks from which the strains originated.

\section{Acknowledgements}

The authors wish to thank Thomas Rebsdorf for technical assistance with the ELISA analysis. The study was supported by EC grant FOOD-CT-2004-506487.

\section{References}

Abildgaard, L., 2008. Development and application of molecular methods for monitoring Clostridium perfringens occurrence and $\alpha$-toxin expression related to necrotic enteritis in broiler chickens. Ph.D. thesis. University of Aarhus, Denmark.

Alape-Gíron, A., Flores-Dias, M., Guillouard, G., Naylor, C.E., Titball, R.W., Rucavado, A., Lomonte, B., Basak, A.K., Gutierrez, J.M., Cole, S.T., Thelestam, M., 2000. Identification of residues critical for toxicity in Clostridium perfringens phospholipase $\mathrm{C}$, the key toxin in gas gangrene. FEBS J. 267, 5191-5197.

Al-Khaldi, S.F., Myers, K.M., Rasooly, A., Chizhikov, V., 2004. Genotyping of Clostridium perfringens toxins using multiple oligonucleotide microarray hybridization. Mol. Cell. Probes 18, 359-367.

Al-Sheikhly, F., Truscott, R.B., 1977. The pathology of necrotic enteritis of chickens following infusion of crude toxins of Clostridium perfringens into the duodenum. Avian Dis. 21, 241-255.

Awad, M.M., Bryant, A.E., Stevens, D.L., Rood, J.I., 1995. Virulence studies on chromosomal alpha-toxin and theta-toxin mutants constructed by allelic exchange provide genetic evidence for the essential role of alpha toxin in Clostridium perfringens mediated gas gangrene. Mol. Microbiol. 15, 191-202.

Banu, S., Ohtani, K., Yaguchi, H., Swe, T., Cole, S.T., Hayashi, H., Shimizu, T., 2000. Identification of novel VirR/VirS-regulated genes in Clostridium perfringens. Mol. Microbiol. 35, 854-864.

Ba-Thein, W., Lyristis, M., Ohtani, K., Nisbet, I.T., Hayashi, H., Rood, J.I., Shimizu, T., 1996. The virR/virS locus regulates the transcription of genes encoding extracellular toxin production in Clostridium perfringens. J. Bacteriol. 178, 2514-2520.

Barbara, A., Trinh, H.T., Glock, R.D., Songer, J.G., 2008. Necrotic enteritisproducing strains of Clostridium perfringens displace non-necrotic enteritis strains from the gut of chicks. Vet. Microbiol. 126, 377-382.

Clark, G.C., Briggs, D.C., Karasawa, T., Wang, X., Cole, A.R., Maegawa, T., Jayasekera, P.N., Naylor, C.E., Miller, J., Moss, D.S., 2003. Clostridium absonum alpha-toxin: new insights into clostridial phospholipase $C$ substrate binding and specificity. J. Mol. Biol. 333, 759-769.

Cooper, K.K., Trinh, H.T., Songer, J.G., 2009. Immunization with recombinant alpha toxin partially protects broiler chicks against experimental challenge with Clostridium perfringens. Vet. Microbiol. 133, 92-97.

Engström, B.E., Fermér, C., Lindberg, A., Saarinen, E., Båverud, V., Gunnarsson, A., 2003. Molecular typing of isolates of Clostridium perfringens from healthy and diseased poultry. Vet. Microbiol. 94, 225-235.
Fernandez-Miyakawa, M.E., Marcellino, R., Uzal, F.A., 2007. Clostridium perfringens type A toxin production in 3 commonly used culture media. J. Vet. Diagn. Invest. 19, 184-186.

Fisher, D.J., Fernandez-Miyakawa, M.E., Sayeed, S., Poon, R., Adams, V., Rood, J.I., Uzal, F.A., McClane, B.A., 2006. Dissecting the contributions of Clostridium perfringens type $C$ toxins to lethality in the mouse intravenous injection model. Infect. Immun. 74, 5200-5210.

Fukata, T., Hadate, Y., Baba, E., Uemura, T., Arakawa, A., 1988. Influence of Clostridium perfringens and its toxin in germ-free chickens. Res. Vet. Sci. 44, 68-70.

Gholamiandekhordi, A.R., Ducatelle, R., Heyndrickx, M., Haesebrouck, F., Van Immerseel, F., 2006. Molecular and phenotypical characterization of Clostridium perfringens isolates from poultry flocks with different disease status. Vet. Microbiol. 113, 143-152.

Hall, T.A., 1999. BioEdit: a user-friendly biological sequence alignment editor and analysis program for Windows 95/98/NT. Nucleic Acids. Symp. Ser. 41, 95-98.

Hough, E., Hansen, L.K., Birknes, B., Jynge, K., Hansen, S., Hordvik, A., Little, C., Dodson, E., Zygmunt, D., 1989. High resolution (1.5A) crystal structure of phopholipase C from Bacillus cereus. Nature 338, 357360.

Justin, N., Walker, N., Bullifent, H., Songer, G., Bueschel, D.M., Jost, H. Naylor, C., Miller, J., Moss, D.S., Titball, R.W., Basak, A.K., 2002. The first strain of Clostridium perfringens isolated from an avian source has an alpha-toxin with divergent structural and kinetic properties. Biochemistry 41, 6253-6262.

Kaldhusdal, M., Hofshagen, M., 1992. Barley inclusion and avoparcin supplementation in broiler diets. 2. Clinical, pathological, and bacteriological findings in a mild form of necrotic enteritis. Poult. Sci. 71, 1145-1153.

Keyburn, A.L., Sheedy, S.A., Ford, M.E., Williamson, M.M., Awad, M.M., Rood, J.I., Moore, J., 2006. Alpha-toxin of Clostridium perfringens is not an essential virulence factor in necrotic enteritis in chickens. Infect. Immun. 74, 6496-6500.

Keyburn, A.L., Boyce, J.D., Vaz, P., Bannam, T.L., Ford, M.E., Parker, D., Di Rubbo, A., Rood, J.I., Moore, R.J., 2008. NetB, a new toxin that is associated with avian necrotic enteritis caused by Clostridium perfringens. PLOS Pathogens 4, e26.

Kulkarni, R.R., Parreira, V.R., Sharif, S., Prescott, J.F., 2007. Immunization of broiler chickens against Clostridium perfringens-induced necrotic enteritis. Clin. Vaccine Immunol. 14, 1070-1077.

Kulkarni, R.R., Parreira, V.R.S., Sharif, S., Prescott, J.F., 2008. Oral immunization of broiler chickens against necrotic enteritis with an attenuated Salmonella vaccine vector expressing Clostridium perfringens antigens. Vaccine 26, 4194-4203.

Ma, M., Ohtani, K., Shimizu, T., Misawa, N., 2007. Detection of a group II intron without an open reading frame in the alpha-toxin gene of Clostridium perfringens isolated from a broiler chicken. J. Bacteriol. 189, 1633-1640.

Mahony, D.E., Moore, T.I., 1976. Stable L-forms of Clostridium perfringens and their growth on glass surfaces. Can. J. Microbiol. 22, 953-959.

Meer, R.R., Songer, J.G., 1997. Multiplex polymerase chain reaction assay for genotyping Clostridium perfringens. Am. J. Vet. Res. 58, $702-705$.

Moreau, H., Pieroni, G., Jolivet-Reynaud, C., Alouf, J.E., Verger, R., 1988. A new kinetic approach for studying phospholipase $C$ (Clostridium perfringens $\alpha$-toxin) activity on phospholipid monolayers. Biochemistry $27,2319-2323$.

Nagahama, M., Michiue, K., Mukai, M., Ochi, S., Sakurai, J., 1998. Mechanism of membrane damage by Clostridium perfringens alpha-toxin. Microbiol. Immunol. 42, 533-538.

Nagahama, M., Otsuka, A., Sakurai, J., 2006. Role of tyrosine-57 and -65 in membrane-damaging and sphingomyelinase activities of Clostridium perfringens alpha-toxin. Biochim. Biophys. Acta 1762, 110-114.

Nauerby, B., Pedersen, K., Madsen, M., 2003. Analysis by pulsed-field gel electrophoresis of the genetic diversity among Clostridium perfringens isolates from chickens. Vet. Microbiol. 94, 257-266.

Naylor, C.E., Eaton, J.T., Howells, A., Justin, N., Moss, D.S., Titball, R.W. Basak, A.K., 1998. Structure of the key toxin in gas gangrene. Nat. Struct. Biol. 5, 738-746.

Olkowski, A.A., Wojnarowicz, C., Chirino-Trejo, M., Laarveld, B., Sawicki, G., 2008. Sub-clinical necrotic enteritis in broiler chickens: novel etiological considerations based on ultra-structural and molecular changes in the intestinal tissue. Res. Vet. Sci. 85, 543-553.

Saint-Joanis, B., Garnier, T., Cole, S.T., 1989. Gene cloning shows the alphatoxin of Clostridium perfringens to contain both sphingomyelinase and lecithinase activities. Mol. Gen. Genet. 219, 453-460.

Sayeed, S., Fernandez-Miyakawa, M.E., Fisher, D.J., Adams, V., Poon, R., Rood, J.I., Uzal, F.A., McClane, B.A., 2005. Epsilon-toxin is required for most Clostridium perfringens type D vegetative culture supernatants 
to cause lethality in the mouse intravenous injection model. Infect. Immun. 73, 7413-7421.

Sheedy, S.A., Ingham, A.B., Rood, J.I., Moore, R.J., 2004. Highly conserved alpha-toxin sequences of avian isolates of Clostridium perfringens. J. Clin. Microbiol. 42, 1345-1347.

Shimizu, T., Ohtani, K., Hirakawa, H., Ohshima, K., Yamashita, A., Shiba, T., Ogasawara, N., Hattori, M., Kuhara, S., Hayashi, H., 2002. Complete genome sequence of Clostridium perfringens, an anaerobic flesh-eater. Proc. Natl. Acad. Sci. 99, 996-1001.

Skånseng, B., Kaldhusdal, M., Rudi, K., 2006. Comparison of chicken gut colonisation by the pathogens Campylobacter jejuni and Clostridium perfringens by real-time quantitative PCR. Mol. Cell. Probes 20, 269279.

Thompson, D.R., Parreira, V.R., Kulkarni, R.R., Prescott, J.F., 2006. Live attenuated vaccine-based control of necrotic enteritis of broiler chickens. Vet. Microbiol. 113, 25-34.

Timbermont, L., Lanckriet, A., Gholamiandehkordi, A.R., Pasmans, F., Martel, A., Haesebrouck, F., Ducatelle, R., Van Immerseel, F., 2008. Origin of Clostridium perfringens isolates determines the ability to induce necrotic enteritis in broilers. Comp. Immunol. Microbiol. Infect. Dis., doi:10.1016/j.cimid.2008.07.001.

Titball, R.W., Leslie, D.L., Harvey, S., Kelly, D., 1991. Hemolytic and sphingomyelinase activities of Clostridium perfringens alpha-toxin are dependent on a domain homologous to that of an enzyme from the human arachidonic acid pathway. Infect. Immun. 59, 1872-1874.

Titball, R.W., Fearn, A.M., Williamson, E.D., 1993. Biochemical and immunological properties of the C-terminal domain of the alpha-toxin of Clostridium perfringens. FEMS Microbiol. Lett. 110, 45-50.

Titball, R.W., 1993. Bacterial phospholipases C. Microbiol. Rev. 57, 347366.

Titball, R.W., Basak, A.K., 2004. The bacterial zinc-metallophospholipases C. J. Toxicol. Toxin Rev. 23, 509-554.

Wages, D.P., Opengart, K., 2003. Necrotic enteritis. In: Saif, Y.M. (Ed.), Diseases of Poultry. 11th ed. Iowa State Press, Ames, IA, USA, pp. 781-785.

Williamson, E.D., Titball, R.W., 1993. A genetically engineered vaccine against the alpha-toxin of Clostridium perfringens protects mice against experimental gas gangrene. Vaccine 11, 1253-1258. 